\title{
ARTICLE
}

\section{Tritium Concentration and Diffusion in Seawater Discharged from Tokai Reprocessing Plant}

\author{
Yuji KOKUBUN*, Hiroki FUJITA, Masanao NAKANO and Shuichi SUMIYA
}

Japan Atomic Energy Agency, 4-33 Muramatsu, Tokai-mura, Naka-gun, Ibaraki,319-1194, Japan

\begin{abstract}
The Tokai Reprocessing Plant has reprocessed the total amount of 1,140 tons of spent fuels since 1977 to the end of fiscal year 2008. During the operation, radioactive liquid effluent has been discharged into the sea from the outlet of the pipeline after the discharge approval. The amount of ${ }^{3} \mathrm{H}$ discharged to the sea was $4.5 \mathrm{PBq}$ in total. Therefore, since 1978, JAEA has sampled seawater around the outlet every month. Tritium concentrations in seawater were analyzed and measured using a liquid scintillation counter. All data were used to calculate the dilution factor which means the ratio of the ${ }^{3} \mathrm{H}$ concentration in seawater to that in liquid effluent. The number of ${ }^{3} \mathrm{H}$ samples with concentrations below the detection limit was 9,079 (82.0\%) and the number of those from the limit to $40 \mathrm{~Bq} / \mathrm{L}$ (as quantification limit) was $1,964(17.7 \%)$. The maximum concentration was $1,700 \mathrm{~Bq} / \mathrm{L}$ at the point just above the outlet in 1979. Moreover, the dilution factors were ranged between 240 and 6,500,000. All ${ }^{3} \mathrm{H}$ concentrations in water were confirmed to be below $60,000 \mathrm{~Bq} / \mathrm{L}$ that was specified by the law and there has been no concern about environmental safety risk.
\end{abstract}

\section{KEYWORDS: tritium ${ }^{\beta}$ H) concentration, diffusion, Tokai Reprocessing Plant (TRP), dilution factor, seawater}

\section{Introduction}

The Tokai Reprocessing Plant (TRP) of Japan Atomic Energy Agency (JAEA) started the opereation in 1977 as the first reprocessing plant in Japan. The TRP has annual reprocessing capacity of 210 tons of spent fuels with the average burn up of 28,000 MWd/MTU and the cooling time of more than 180 days as a design-base. The annual reprocessing capacity is about one tenth compared with the La Hague reprocessing plant (UP2: $800 \mathrm{tU}, \mathrm{UP} 3: 1000 \mathrm{tU})$ in France and with the Sellafield one (B205: $1500 \mathrm{tU}$, THORP: $1200 \mathrm{tU}$ ) in United Kingdom. The TRP has reprocessed the total amount of 1,140 tons of spent fuels since 1977 to the end of fiscal year 2008 .

During the operation, radioactive liquid effluent has been discharged into the sea from the outlet of the pipeline stretching about $3.7 \mathrm{~km}$ from shoreline, after the discharge approval (Until 1991, the outlet had been set on $1.8 \mathrm{~km}$ offshore).

Tritium $\left({ }^{3} \mathrm{H}, \mathrm{T}\right)$ emits beta ray $\left(\beta_{\max }=18.6 \mathrm{keV}\right)$ with half-life of $12.33 \mathrm{y}$. The dose coefficient for intakes of HTO is $1.8 \times 10^{-11} \mathrm{~Sv} / \mathrm{Bq}^{1)}$, which is smaller than other coefficients of radionuclides. However, the total amount of the ${ }^{3} \mathrm{H}$ is the largest amount in effluent of radioactivities discharged from the TRP.

Therefore, since 1978, JAEA has conducted radiological monitoring (such as ${ }^{3} \mathrm{H}$, gross beta and ${ }^{137} \mathrm{Cs}$ ) of seawater around the outlet every month. ${ }^{2)}$ Tritium concentration in seawater was analyzed and measured using a liquid scintillation counter. All data were used to calculate the dilution factor which means the ratio of the ${ }^{3} \mathrm{H}$ concentration in seawater to that in liquid effluent.
Moreover, the ${ }^{3} \mathrm{H}$ concentrations in seawater and the dilution factors were obtained with passing time after end of effluent release and compared with the calculation by the simple diffusion model.

This paper describes about 11 thousands concentration data obtained by the end of fiscal year 2008, which were analyzed in order to understand the behavior of ${ }^{3} \mathrm{H}$ and to confirm the public safety.

\section{Tritium Discharge from the Tokai Reprocess- ing Plant}

Figure 1 shows the actual discharge of ${ }^{3} \mathrm{H}$ to sea from the TRP. The maximum annual ${ }^{3} \mathrm{H}$ amount was about 0.5 $\mathrm{PBq}$ in 1994, which was less than one fourth of the maximum authorised discharge of ${ }^{3} \mathrm{H}$ activity. The TRP discharged 4.5 $\mathrm{PBq}$ of ${ }^{3} \mathrm{H}$ to the sea during the operation in all. The discharged amount was quite lower than both amounts of $186 \mathrm{EBq}$ released from nuclear weapon testing and of $1.3 \mathrm{EBq} / \mathrm{a}$ originated from the interaction of high energy cosmic ray with xenon. The distribution from the both to the ${ }^{3} \mathrm{H}$ concentration in seawater was estimated to be about $0.1 \mathrm{~Bq} / \mathrm{L}$ in $2000{ }^{2)}$

Normalized ${ }^{3} \mathrm{H}$ discharge amount (in $\mathrm{GBq} / \mathrm{GWa}$ ) defines ${ }^{3} \mathrm{H}$ discharge amount per generated electric energy by the reprocessed spent fuel. Normalized ${ }^{3} \mathrm{H}$ discharge amount of the TRP was $5.6 \times 10^{5}(\mathrm{GBq} / \mathrm{GWa})$ at maximum, which was approximately equal to those of the La Hague reprocessing plant in France and of the Sellafield one in United Kingdom. ${ }^{3)}$ The ${ }^{3} \mathrm{H}$ discharge of liquid effluent was relatively proportional to the amounts of fuel reprocessed, being independent of the type of reprocessing plant. 


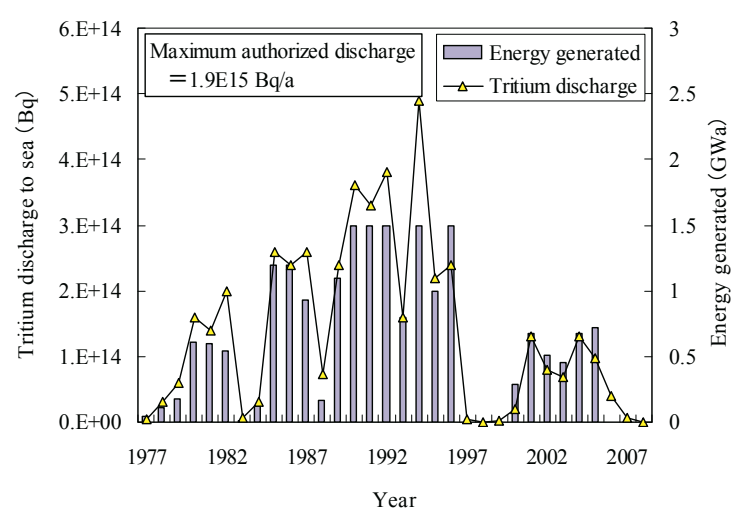

Fig.1 Tritium amount discharged to sea and generated energy of the spent fuel reprocessed in the Tokai Reprocessing Plant.

\section{Analysis and Evaluation Method \\ 1. Monitoring Methodology}

Surface seawater samples were collected at thirty points around the TRP's outlet described in Nakano et al. ${ }^{2)}$ Figure 2 shows an overview of discharge and sampling points in the sea around the TRP. The outlet is located on $3.7 \mathrm{~km}$ offshore and $24 \mathrm{~m}$ depth, but had been established at $1.8 \mathrm{~km}$ offshore until 1991.

All samples were purified by distillation, and $8 \mathrm{ml}$ of the purified water and $12 \mathrm{ml}$ of liquid scintillation cocktail (Aquasol-2, Perkinelmer) were mixed well in a low potassium glass vial under hot water. After cooling it for over 1 day at about $15{ }^{\circ} \mathrm{C}$ in dark, most of samples were measured for 250 minutes (50 min. x 5 times) by a low background liquid scintillation counter (LSC; TRICARB 2260XL etc., Packard Co.). The detection limit (DL) in this typical measurement condition was calculated about $4 \mathrm{~Bq} / \mathrm{L}$ on the basis of 3 times of a standard deviation using background water collected from deep spring water.

\section{Diffusion Calculation Method}

Empirical equation estimating ${ }^{3} \mathrm{H}$ concentration was used in diffusion calculation as shown in Eq.(1). The equation was utilized in the safety assessment of the TRP to evaluate the ${ }^{3} \mathrm{H}$ concentration in seawater from the outlet to the stream direction. Here, 'Erf' shows the error function as shown in Eq.(2).

$$
\begin{aligned}
& C=\frac{q}{u H Y} \operatorname{Erf}\left(\frac{Y u}{4 \sqrt{a x}}\right), \\
& \operatorname{Erf}(y)=\frac{2}{\pi} \int_{0}^{y} e^{-t^{2}} d t
\end{aligned}
$$

where $\mathrm{C}$ is the ${ }^{3} \mathrm{H}$ concentration in seawater at stream direction $\left(\mathrm{Bq} / \mathrm{m}^{3}\right), q$ is the ${ }^{3} \mathrm{H}$ discharge rate $(\mathrm{Bq} / \mathrm{s})$ from the outlet, $u$ is the flow velocity in sea $(\mathrm{m} / \mathrm{s}), 690 \mathrm{~cm}(460 \mathrm{~cm}$ until 1991) is substituted for $H$ as depth of vertical mixing layer, $200 \mathrm{~cm}$ is substituted for $Y$ as the horizontal diffusion width at stream direction, $a$ is 0.1415 as a constant and $x$ is the distance from the outlet.

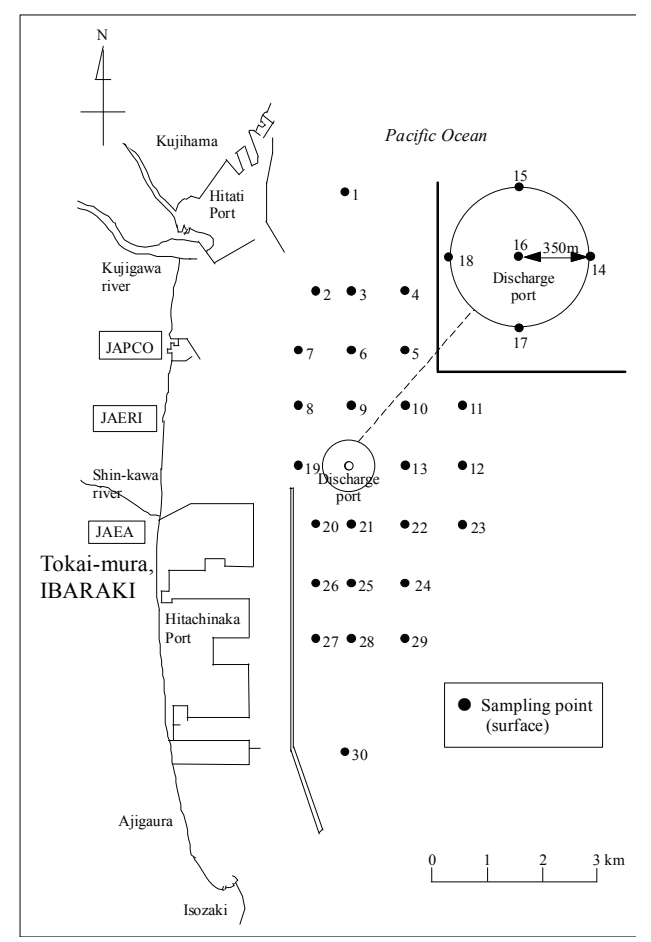

Fig.2 Seawater sampling points in this study.

(left : from July 1978 to September 1991, right : from October 1991 to June 2008) 


\section{Results}

\section{Tritium Concentration in Seawater}

The ${ }^{3} \mathrm{H}$ concentrations in seawater collected around the TRP have been measured for 30 years since 1978 and were already obtained over ten thousands data. Table 1 shows the list of ${ }^{3} \mathrm{H}$ concentrations summarized at individual 10 years.

Table 1 Number of ${ }^{3} \mathrm{H}$ concentration data in each range

\begin{tabular}{cccc}
\hline Sampling & \multicolumn{3}{c}{ Number } \\
\cline { 2 - 4 } period & $<\mathrm{DL}$ & $\mathrm{DL} \sim 40(\mathrm{~Bq} / \mathrm{L})$ & $>40(\mathrm{~Bq} / \mathrm{L})$ \\
\hline $1978.7-1988.6$ & 2,295 & 1,290 & 15 \\
$1988.7-1998.6$ & 3,267 & 323 & 10 \\
$1998.7-2009.3$ & 3,517 & 351 & 2 \\
\hline Total & 9,079 & 1,964 & 27 \\
\hline
\end{tabular}

The number of ${ }^{3} \mathrm{H}$ concentrations below the DL was $9,079(82.0 \%)$ and the number of those from the DL to 40 $\mathrm{Bq} / \mathrm{L}$ (as quantification limit) was 1,964 (17.7\%), namely these concentrations occupied over $99.7 \%$ in all monitoring data. The highest concentration was $1,700 \mathrm{~Bq} / \mathrm{L}$ at the point just above the outlet in 1979 and was not caused by accidental discharge but due to sampling the seawater during the discharge etc. All the concentrations were confirmed to be those below $60,000 \mathrm{~Bq} / \mathrm{L}$ of ${ }^{3} \mathrm{H}$ concentration limit in water fixed by law. In the past 30 years, discharge amount and concentration of ${ }^{3} \mathrm{H}$ were below the limit decided by the safety regulation and by the law, respectively.

Occurrence frequency of ${ }^{3} \mathrm{H}$ concentrations above DL had the decrease with every 10 years. It was supposed that the tendency could be caused by both decrease of influences of atmospheric nuclear tests and of reprocessing amount of the fuels. Moreover, the tendency might be influenced by movement of the outlet in 1991 because depth of discharge of liquid effluent in the sea was changed from $16 \mathrm{~m}$ to $24 \mathrm{~m}$ as described by Nakano et al. ${ }^{2)}$

Table 2 summarizes the ${ }^{3} \mathrm{H}$ concentration data at each distance from the outlet to each sampling point. It was obvious that the concentrations were decreased with the distances. This tendency indicates that the liquid effluent with ${ }^{3} \mathrm{H}$ could be diffused by stream after discharge. Diffusion way of ${ }^{3} \mathrm{H}$ effluent with passing time after the discharge is studied in section IV.3.

\section{Dilution Factor}

Table 2 shows the dilution factors which mean the ratio of the initial tritium concentration in effluent to that in seawater. The concentrations in seawater above the DL were used in the calculation of the factors. As a result, the factors ranged between 240 and 6,500,000. Four data of dilution factors ( $0 \mathrm{~km} ; 240,740,840,0.35 \mathrm{~km} ; 400)$ below 1,000 were relatively smaller than the other data. Three data in these four were obtained in seawater collected on the outlet throughout the discharge. Another was obtained in seawater collected at $0.35 \mathrm{~km}$ around the outlet after the discharge. At that time, ${ }^{3} \mathrm{H}$ concentration in the effluent was lower than those in the other effluents. Moreover, ${ }^{3} \mathrm{H}$ concentration in the seawater was a little higher than in the other seawaters. Therefore, it would not be considered as a direct influence from the discharge, but it was regarded as the influence by the previous discharges before collected these samples or by discharged effluents from the other facilities. Change of the dilution factors with passing time after discharge is described below. In terms of distances from the outlet to each sampling point, the dilution factors were increased with the distance as expected.

\section{Diffusion of ${ }^{3} \mathrm{H}$ Discharged from the TRP}

Figure 3 shows ${ }^{3} \mathrm{H}$ concentration dependency on both changes of the distance and the elapsed time in the 15 cases of the discharge from 1978 to 2009 when ${ }^{3} \mathrm{H}$ concentrations in the seawaters were relatively higher than in the other seawaters.

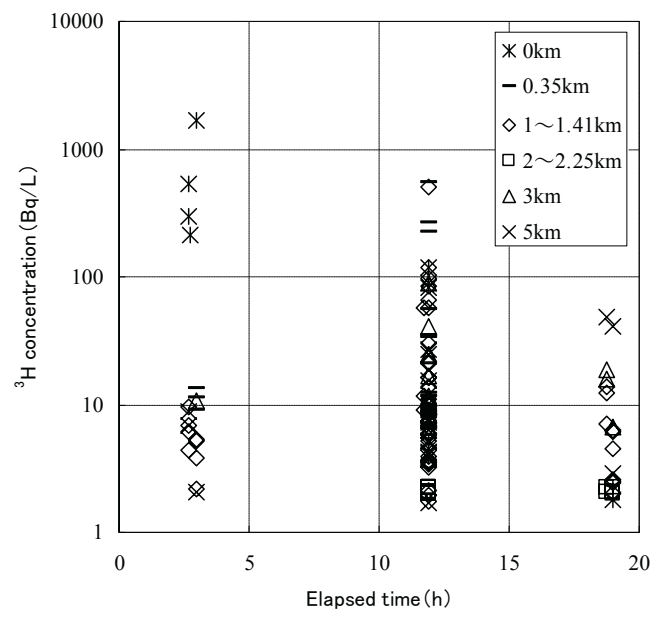

Fig.3 Tritium concentration dependency on changes of the distance and the elapsed time. (21/Dec/1979 etc.)

Table 2 Concentration and dilution factor of ${ }^{3} \mathrm{H}$ in surface seawater

\begin{tabular}{cccc}
\hline Distance from discharge port $(\mathrm{km})$ & Number detected & $\begin{array}{c}{ }^{3} \mathrm{H} \text { concentration } \\
(\mathrm{Bq} / \mathrm{L})\end{array}$ & Dilution factor \\
\hline $0(\mathrm{n}=369)$ & 112 & $1.1 \sim 1,700$ & $240 \sim 6,500,000$ \\
$0.35(\mathrm{n}=1,476)$ & 234 & $1.2 \sim 550$ & $400 \sim 4,500,000$ \\
$1 \sim 1.41(\mathrm{n}=2,952)$ & 664 & $0.85 \sim 500$ & $1,100 \sim 5,900,000$ \\
$2 \sim 25(\mathrm{n}=3,321)$ & 448 & $1.0 \sim 82$ & $1,200 \sim 4,900,000$ \\
$3 \sim 3.16(\mathrm{n}=2,214)$ & 339 & $1.0 \sim 120$ & $1,200 \sim 4,000,000$ \\
$5(\mathrm{n}=738)$ & 194 & $1.7 \sim 83$ & $1,800 \sim 4,700,000$ \\
\hline
\end{tabular}

$\mathrm{n}$ : total number of ${ }^{3} \mathrm{H}$ concentration data 
In the figure, the ${ }^{3} \mathrm{H}$ concentrations at the south of the outlet were summarized to observe diffusion of ${ }^{3} \mathrm{H}$ discharged from the outlet because the stream direction at the outlet was mainly south. ${ }^{4)}$ The concentrations above the DL were observed for samples collected in the seawater around the outlet, which were expected to give decreased values lower than the limits in $20 \mathrm{~h}$ or more later. On the other hand, the concentrations were below the DL for samples collected at 2 or $3 \mathrm{~km}$ away from the outlet immediately, but those exceeded the limits $11 \mathrm{~h}$ later and then decreased to the limits $20 \mathrm{~h}$ later, again. From these results, the apparent velocity of surface seawater was calculated to be approximately $7 \mathrm{~cm} / \mathrm{s}$. The velocity was relatively slower than that obtained in previous diffusion experiment conducted in sodium fluorescein. However, the velocity could be faster than our study because our observation data were scattered in view point of sampling time.

\section{Comparison with the Diffusion Calculation}

Figure 4 shows the comparative results between the observed and the calculated ${ }^{3} \mathrm{H}$ concentration over $40 \mathrm{~Bq} / \mathrm{L}$. As a result, all observed concentrations were lower than the calculated ones and the concentration ratios were about $1 / 1$ to $1 / 100$ time of the calculated concentrations.

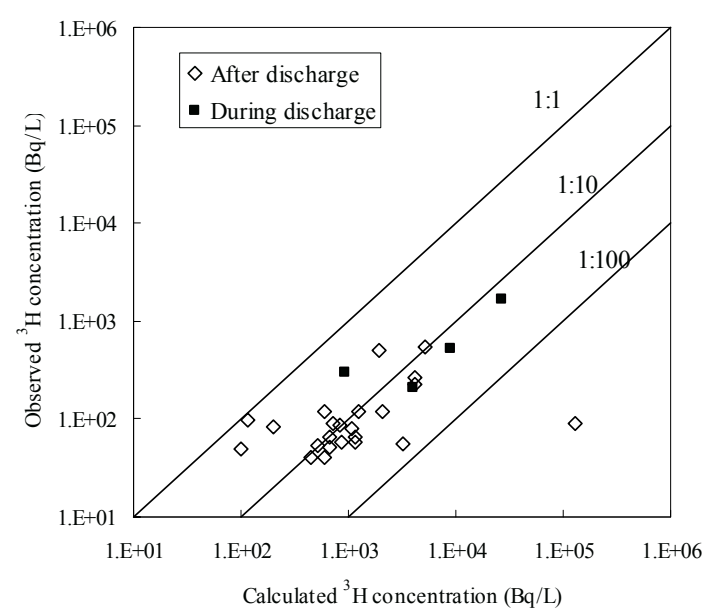

Fig.4 Comparison between the observed and calculated ${ }^{3} \mathrm{H}$ concentration over $40 \mathrm{~Bq} / \mathrm{L}$.
Therefore, diffusion calculation gave conservative results, and it was confirmed that the calculation was appropriate as a safe estimation.

\section{Conclusions}

The ${ }^{3} \mathrm{H}$ concentration in seawater collected around the TRP have been measured for samples above ten thousands. As a result, the ${ }^{3} \mathrm{H}$ was occationaly detected due to the discharge from the TRP. However, all the concentrations were lower than ones expected with diffusion calculation and were confirmed to be below $60,000 \mathrm{~Bq} / \mathrm{L}$ of ${ }^{3} \mathrm{H}$ concentration limit in water fixed by the law. Moreover, the calculation used in safety assessment showed conservative result compared with observed concentrations.

\section{References}

1) Health Protection Agency, Review of risks from tritium,United Kingdom,42-43(2007).

2) M.Nakano, Y.Kokubun, M.Takeishi, "Tritium concentration and diffusion in seawater discharged from Tokai Reprocessing Plant,"Nihon-Hokenbuturi-Gakkai Shi(J.Jpn.Health Phys.), 44[1], 60-65 (2009), [in Japanese]

3) T.Mizutani, J.Koarashi, M.Takeishi, "Monitoring of low-level radioactive liquid effluent in Tokai Reprocessing Plant,"J.Nucl.Sci.Technol., 46[7], 665-672 (2009).

4) M.Nakano, H.Isozaki, T.Isozaki, M.Nemoto, K.Hasunuma, T.Kitamura, "Wind effect on currents in a thin surface layer of coastal waters faced open-sea,"Nihon-Kaiyou Gakkai Shi(J.Oceanoraphy Soc.Jpn.), 18[1],37-55(2009),[in Japanese]. 